\title{
Magnesium Sulphate Versus Sildenafil in the Treatment of Persistent Pulmonary Hypertension of the Newborn
}

\author{
Fawzan Shaltout $^{\mathrm{a}, \mathrm{c}}$, Ranya Hegazy ${ }^{\mathrm{a}}$, Hana Aboulghar ${ }^{\mathrm{a}}$, Lamiaa Abdel Motelb ${ }^{\mathrm{b}}$
}

\begin{abstract}
Background: The present study aimed at evaluating the efficacy of both oral sildenafil and magnesium sulfate $\left(\mathrm{MgSO}_{4}\right)$ in the treatment of persistent pulmonary hypertension of the newborn (PPHN).
\end{abstract}

Methods: A randomized clinical trial including 200 neonates diagnosed clinically with PPHN and confirmed by echocardiography who were randomly divided into two groups: group S; included 100 neonates treated with sildenafil, and group $\mathrm{M}$ included 100 neonates treated with $\mathrm{MgSO}_{4}$.

Results: Both groups showed a significant improvement in their pulmonary artery pressure 48 hours after therapy as compared to their baseline measurements. However EPAP was significantly lower five days after therapy in neonates receiving sildenafil (24.7 $\pm 4.3 \mathrm{mmHg})$ as compared to those receiving $\mathrm{MgSO}_{4}(36.2 \pm 3.6$ $\mathrm{mmHg}) ; \mathrm{P}=0.012$. The sildenafil group also showed a significantly shorter duration to improvement of oxygenation $(\mathrm{P}=0.02)$ and a shorter duration on mechanical ventilation $(\mathrm{P}=0.03)$. Limited side effects and comparable survival rates were observed in both groups.

Conclusions: Sildenafil is a more effective therapeutic option in the treatment of PPHN as compared to $\mathrm{MgSO}_{4}$.

Manuscript accepted for publication February 7, 2012

\footnotetext{
${ }^{a}$ Department of Pediatrics, Faculty of Medicine, Cairo University, Egypt

${ }^{\mathrm{b}}$ Department of Neonatology, Ahmed Maher Hospital, Egypt

${ }^{\mathrm{c} C}$ orresponding author: Ranya Hegazy, 3 Ramez st. off Shehab st,

Mohandeseen Giza, apartment 51, Egypt.

Email: r_hegazy@hotmail.com
}

doi:10.4021/ijcp8w
Keywords: Persistent pulmonary hypertension of the newborn (PPHN); Sildenafil; Magnesium sulfate $\left(\mathrm{MgSO}_{4}\right)$; Randomized clinical trial

\section{Introduction}

Persistent pulmonary hypertension in the newborn (PPHN) is a neonatal emergency due to failure to achieve normal cardiopulmonary adaptation following delivery. PPHN still remains a challenging condition with high morbidity and mortality [1]. It occurs in approximately 1.9 per 1000 newborns and may be more frequent in developing countries due to lack of optimum childbirth conditions. PPHN can occur as a primary condition or secondary to meconium aspiration, respiratory distress syndrome, infection or congenital diaphragmatic hernia [2].

A variety of treatment options includes hyperventilation, pressor agents, surfactant, sedation, alkalinization, vasodilatation e.g (tolazoline, inhaled nitric oxide, magnesium sulfate, adenosine, sildenafil) and extracorporeal membrane oxygenation ECMO [3]. The aim of treatment is to lower pulmonary vascular resistance, maintain systemic blood pressure, reverse right to left shunt, and improve arterial oxygen saturation [4].

There is strong evidence for the use of inhaled nitric oxide (NO) and ECMO in the treatment of PPHN. However, many developing countries and resource limited centers do not have the funds or the technical expertise required for these expensive therapies [5].

Magnesium sulfate $\left(\mathrm{MgSO}_{4}\right)$ is a natural $\mathrm{Ca}$ channel blocker that antagonizes $\mathrm{Ca}$ ion entry into smooth muscle cell thus promoting vasodilatation. $\mathrm{MgSO}_{4}$ is a safe and cheaper alternative for first line treatment in moderate PPHN and was chosen to be an alternative therapy for PPHN when other conventional treatments fail, are contraindicated or are not available [6].

Sildenafil is a potent and selective inhibitor of cGMPspecific phosphodiesterase 5 (PDE5). This isoenzyme metabolizes cGMP which is the second- messenger of NO and a principle mediator of smooth muscle relaxation and vaso- 
Table 1. Clinical Characteristics of Both Groups

\begin{tabular}{|c|c|c|c|}
\hline & Group S & Group M & P-value \\
\hline \multicolumn{4}{|l|}{ Sex } \\
\hline Male & $54(54 \%)$ & $58(58 \%)$ & \\
\hline Female & $46(46 \%)$ & $42(42 \%)$ & 1 \\
\hline Gestational age (weeks) & $37.5 \pm 1.1$ & $37.1 \pm 1.14$ & 0.6 \\
\hline Mean Age (days) & $4.2 \pm 2.5$ & $3.6 \pm 1.3$ & 0.81 \\
\hline \multicolumn{4}{|l|}{ Mode of Delivery } \\
\hline Vaginal delivery & $29(29 \%)$ & $31(31 \%)$ & \\
\hline Cesarean Section & $71(71 \%)$ & $69(69 \%)$ & 1 \\
\hline
\end{tabular}

dilatation. By inhibiting the hydrolytic breakdown of cGMP, sildenafil prolongs the action of cGMP. This results in augmented smooth muscle relaxation and cause pulmonary vasodilatation [7]. Sildenafil decreases pulmonary vascular resistance in pulmonary hypertensive neonate [8].

\section{Aim of the work \\ Although both oral sildenafil and $\mathrm{MgSO}_{4}$ have been studied independently in the treatment of PPHN, randomized clini- cal trials comparing both are limited. The aim of this work was to study the efficacy of both modalities in the treatment of newborns with PPHN and compare the time interval to improvement, degree of improvement, side effects and out- come.}

\section{Patients and Methods}

This is a randomized clinical trial study that included 200 neonates recruited from three tertiary referral neonatal units from May 2008 to May 2011. The study protocol was approved by the institution review board and informed consent was obtained from parents prior to inclusion.

Candidates for the present work were neonates with cyanosis, hypotension and respiratory distress who showed an improvement when hyperventilated with $100 \% \mathrm{O}_{2}$. Parameters of improvement were an increase in $\mathrm{PaO}_{2}>30$ $\mathrm{mmHg}$, a lowering $\mathrm{PaCO}_{2}$ and an increasing $\mathrm{pH}$. They were then confirmed to have PPHN by echocardiography through measurement of their estimated pulmonary artery pressure (EPAP). Neonates with EPAP more than $50 \mathrm{mmHg}$ were included. Echocardiography was performed by portable echocardiography "sonosite" using probes 5 - $7 \mathrm{mHz}$. Any neonates with congenital cyanotic heart disease (CCHD), respiratory distress syndrome (RDS) or hypoxic ischemic encephalopathy (HIE) were excluded.

The primary investigator blindly chose a card coded $\mathrm{S}$ (sildenafil group) or $\mathrm{M}\left(\mathrm{MgSO}_{4}\right.$ group) that placed neonates in their respective groups; one hundred neonates in each. Neonates continued to receive the standard treatment of PPHN (hyperventilation, inotropes, oxygenation and sedation) in addition to their assigned therapies.

Group $\mathrm{S}$ was treated with oral sildenafil in a dose of 1 $\mathrm{mg} / \mathrm{kg} / 6 \mathrm{hr}$ by nasogastric tube. The solution for sildenafil was prepared by crushing a $50 \mathrm{mg}$ tablet of sildenafil in distilled water to achieve a concentration of $2 \mathrm{mg} / \mathrm{ml}$. Complications of sildenafil were monitored as regards the development of hypotension, bleeding tendency, diarrhea and rash.

Group $\mathrm{M}$ was treated with $\mathrm{MgSO}_{4}$ at a loading dose of $200 \mathrm{mg} / \mathrm{kg}$ infused over 30 minutes, followed by maintenance dose of $20-50 \mathrm{mg} / \mathrm{kg} / \mathrm{hr}$. Complications of $\mathrm{MgSO}_{4}$ were monitored as regards the development of hypotension, CNS depression, urinary retention, GIT disturbance and calcium and potassium disturbance.

The primary outcome measure was duration to drop in EPAP as measured by echocardiography to below $25 \mathrm{mmHg}$. Baseline measurement was taken before start of therapy (P1), at 48 - 72hrs later (P2), and 5 days after start of therapy (P3). Estimation of pulmonary artery pressure was done by measuring the peak velocity of tricuspid regurge (TR). The peak velocity of TR, measured with Doppler ultrasound, is converted into a pressure drop by application of the modified Bernoulli equation, $\mathrm{P}=4 v^{2}, \mathrm{p}$ is the pressure drop ( $\mathrm{mmHg}$ ) and $\mathrm{v}$ is the velocity of blood $(\mathrm{m} / \mathrm{s})$. The drop in pressure from the right ventricle (RV) to the right atrium (RA) in systole can be assessed as follows: RV pressure $-\mathrm{RA}$ pressure $=$ $4 \times(\text { TR jet velocity })^{2}$.

Secondary outcome measures used were time interval to improvement of oxygen saturation and blood gases and duration of ventilation. Complications of either line of therapy were monitored and recorded. 
Table 2. Baseline Signs of PPHN Among Both Groups

\begin{tabular}{|c|c|c|c|c|}
\hline & Groups & Number & Percentage & P-value \\
\hline \multirow{7}{*}{ Respiratory distress } & Mild & 10 & 10 & 0.150 \\
\hline & Moderate & 32 & 32 & \\
\hline & Severe & 58 & 58 & \\
\hline & & & & \\
\hline & Mild & 12 & 30 & \\
\hline & Moderate & 29 & 0 & \\
\hline & Severe & 59 & 59 & \\
\hline \multirow{3}{*}{ Cyanosis } & Group S & 58 & 58 & \\
\hline & & & & 1.000 \\
\hline & Group M & 59 & 59 & \\
\hline \multirow{2}{*}{ Murmur } & Group S & 71 & 71 & 0.656 \\
\hline & Group M & 68 & 68 & \\
\hline \multirow{2}{*}{$\begin{array}{l}\text { Cardiomegaly by chest } \\
\text { X-ray }\end{array}$} & Group S & 59 & 59 & 0.650 \\
\hline & Group M & 63 & 63 & \\
\hline
\end{tabular}

\section{Statistical method}

Data were statistically described in term of range, mean \pm standard deviation $( \pm \mathrm{SD}$ ), median, frequencies (number of cases) and relative frequencies (percentages) when appropriate. Comparison of quantitative variables between the study groups was done using Mann Whitney $U$ test for independent samples when not normally distributed. For comparing categorical data, Chi square $\left(\mathrm{X}^{2}\right)$ test was performed. Exact test was used instead when the expected frequency is less than 5. Survival analysis was done for the different outcome measures using Kaplan Maier statistics. A probability value (P value) less than 0.05 was considered statistically significant. All statistical calculations were done using computer programs Microsoft Excel 2003 (Microsoft Corporation, NY, and USA) and SPSS (Statistical Package for the Social Science; SPSS Inc., Chicago, IL, USA) version 15 for Microsoft Windows.

\section{Results}

Two hundred neonates were included in the present work. One hundred were randomly assigned to the sidenafil therapy (group S) and one hundred to $\mathrm{MgSO}_{4}$ therapy (group $\mathrm{M}$ ). The descriptive data of the study group are shown in table 1.
Both groups showed no significant differences in their sex distribution, gestational ages, mean ages at start of therapy or modes of delivery.

As regards clinical manifestations of PPHN, our study group presented with various degrees of respiratory distress, cyanosis, murmur and cardiomegaly diagnosed by chest Xray and echocardiography (Table 2).

An associated patent ductus arteriosus (PDA) was noted in $82(82 \%)$ of group $\mathrm{S}$ and in $76(76 \%)$ of group $\mathrm{M} \mathrm{P}=0.54$. According to the size and hemodynamic significance of the PDA, attempt at medical closure was indicated in forty-one neonates in group $\mathrm{S}$ and thirty-seven patients in group $\mathrm{M}$. Urine output, kidney function tests and platelet counts were estimated prior to therapy. Impairment of any parameter favored the use of oral ibuprofen over indomethacin. Indomethacin was used in $29(70 \%)$ of those indicated for closure in group S and in $24(65 \%)$ of those indicated for closure in group $\mathrm{M}$.

\section{Primary measure of outcome}

Both groups showed significant drop of the EPAP at $48-72$ hours and five days after the initiation of either therapy as compared to baseline EPAP.

When comparing EPAP measurements in both group $\mathrm{S}$ and group $\mathrm{M}$ at baseline (P1) and at $48-72$ hours (P2) no 
Table 3. Estimated Pulmonary Artery Pressure (EPAP) in our Study Groups

\begin{tabular}{|c|c|c|c|c|}
\hline & Groups & Mean & Std. deviation & P. value \\
\hline \multirow{2}{*}{$\begin{array}{l}\text { EPAP before treatment }(\mathrm{P} 1) \\
\mathrm{mmHg}\end{array}$} & Group S & 61.5 & \pm 9.8 & \multirow{2}{*}{0.731} \\
\hline & Group M & 58.1 & \pm 8.6 & \\
\hline \multirow{2}{*}{$\begin{array}{l}\text { EPAP } 48 \text { hours after treatment } \\
(\mathrm{P} 2) \mathrm{mmHg}\end{array}$} & Group S & 40.4 & \pm 12.2 & \multirow{2}{*}{0.255} \\
\hline & Group M & 42.8 & \pm 11.5 & \\
\hline \multirow{2}{*}{$\begin{array}{l}\text { EPAP } 5 \text { days after treatment (P3) } \\
\mathrm{mmHg}\end{array}$} & Group S & 24.7 & \pm 4.3 & \multirow{2}{*}{0.012} \\
\hline & Group M & 36.2 & \pm 3.6 & \\
\hline
\end{tabular}

significant differences were detected. However five days after therapy group $\mathrm{S}$ had a significantly lower EPAP (P3) of $24.7 \pm 3.8 \mathrm{mmHg}$ than that in group $\mathrm{M}(36.2 \pm 3.2 \mathrm{mmHg})$ $(\mathrm{P}=0.012)($ Table 3$)$.

\section{Secondary measures of outcome}

An important factor indicating improvement of patient is the time interval to normalization of oxygen saturation and arterial blood gases. Group S showed a significantly shorter interval to normalization of oxygen saturation, arterial blood gases and a significantly shorter duration of ventilation as compared to group M (Table 4).

\section{Complications of therapy}

Looking at complications we found that in group $\mathrm{S}$, twenty patients developed hypotension $(20 \%)$ and four suffered bleeding (4\%). None developed rash or diarrhea. While in group M, five neonates developed CNS depression (5\%) and twenty developed hypotension (20\%). None developed hypocalcaemia, or GIT disturbances.

\section{Mortality}

Outcome in both groups was compared using Kaplan Maier survival analysis. Both groups showed similar outcomes (P $=1)$, ten babies $(10 \%)$ died in group $\mathrm{S}$ with a comparable mortality rate of $12 \%$ in group M. Of these babies, six died out of sepsis; three in each group.

\section{Cost of therapy}

The final cost analysis showed that sildenafil is a cheaper therapeutic option for the treatment of PPHN, despite being a more expensive medication than $\mathrm{MgSO}_{4}$ because of the significantly shorter duration of ventilation and hospitalization.

\section{Discussion}

PPHN is a serious neonatal emergency, which contributes to neonatal hypoxemia that is often refractory and is associated with a high mortality. The most effective types of treatment of PPHN including iNO and ECMO are not available in many of the developing countries, including Egypt. Hence search for other options is crucial. Our study aimed at comparing intravenous $\mathrm{MgSO}_{4}$ and oral sildenafil as possible therapies in the management of PPHN and concluded that both are effective and relatively safe with comparable rates of outcome and adverse effects.

There is extremely limited information on the use of $\mathrm{MgSO}_{4}$ for PPHN. Five uncontrolled clinical studies were identified by the Cochrane collaboration, published in 2007 $[6,9-12]$. Four of these studies were performed on full term babies and hence had a comparable gestational age to our study group $(\mathrm{M}=37.1+1.14$ week $)$. All of these studies used a comparable dosage plan with a loading dose of $200 \mathrm{mg} / \mathrm{kg}$ over 30 minutes that was followed by a continuous infusion of $20-150 \mathrm{mg} / \mathrm{kg} / \mathrm{hrs}$.

We did not measure the serum magnesium level in the present work, however the blood pressure was monitored and in response to hypotension, $\mathrm{MgSO}_{4}$ infusion was temporarily discontinued and saline infusion given. Hypotension was observed in twenty of our patients $(20 \%)$ and was also reported by Daffa and Milaat [11]. Transient bradycardia was observed by Abu-Osba [9], but not noted in the present work. We noted flaccidity in one of our patients. However, other side effects of $\mathrm{MgSO}_{4}$ (hypocalcaemia and GIT disturbance) were not found in the present work which is in agreement with other studies [6, 9-11]. Respiratory depression can 
Table 4. Duration to Improvement of $\mathrm{SaO}_{2}$ and $\mathrm{ABG}$ and Duration of Ventilation by Days in our Study Groups

\begin{tabular}{llcc}
\hline & Groups & Median & P. value \\
\hline $\begin{array}{l}\text { Time interval to normalization } \\
\text { of } \mathrm{SaO}_{2} \text { (days) }\end{array}$ & Group S & 2.2 & 0.02 \\
\hline & Group M & Mean & SD \\
\hline $\begin{array}{l}\text { Time interval to normalization } \\
\text { of ABG (days) }\end{array}$ & Group S & 2.45 & \pm 0.8 \\
& Group M & 3.70 & \pm 1.2 \\
Guration of ventilation (days) & Group S & 4.8 & \pm 2.15 \\
\hline
\end{tabular}

not be commented upon as $\mathrm{MgSO}_{4}$ was administered during mechanical ventilation.

We did not follow up our patients for adverse neurological effects but studies that did, found patients to have normal neurological examination at 1 year $[6,9]$.

Our primary outcome measure was drop in EPAP by echocardiographic evaluation (88 patients improved). Not all other studies followed patients up by echocardiography. Abu-Osba [9] reported a comparable rate of improvement.

Secondary outcome measure was improvement of oxygenation measured by changes in partial oxygenation pressure and ventilatory requirements where a significant improvement of patients' oxygenation parameters was noted at 48 hours as agreed upon by previous studies [6, 9-11].

Eighty eight out of the hundred neonates in the study group, treated with magnesium sulphate survived. A study by Abu-Osba [9] reported a survival rate of seven out of nine, and Daffa [11] reported a survival rate of seven out of eight. In studies by Tolsa et al [10] and Chandran et al., [6] all included study subjects survived. Three of our patients who died suffered septicemia and hence cannot be considered failure of therapy.

Data on use of sildenafil in PPHN is currently limited to a few case reports [13] and small series [14, 15]. Randomized controlled trials and pharmacokinetic data for optimal dosage are also limited.

Our clinical trial used a sildenafil dosage of $1 \mathrm{mg} / \mathrm{kg} / 12$ hrs; no consensus has been reached as regards optimal dosage. In a study done by Baquero [16] the dosage was $1 \mathrm{mg} /$ $\mathrm{kg} / 6 \mathrm{hrs}$ while the dose was $0.5 \mathrm{mg} / \mathrm{kg} / 12 \mathrm{hrs}$ in a study by Oliver and Webb [17].

Two uncontrolled clinical studies were identified by Cochrane collaboration, published in 2007 [16, 18] and updated in 2011 [19]. They were performed on full term babies and showed improvement in oxygenation measures by changes in $\mathrm{PaO}_{2}$ and ventilator requirement; which is in agreement with our study. Khorana, 2011 [20] reported improvement of oxygenation in full term babies with the use of sildenafil. However, hypotension was a concern in their study and it was noted among $20 \%$ of the studied babies on sildenafil in the present work.

In agreement with our results, a recent randomized clinical trial comparing 34 neonates on $\mathrm{MgSO}_{4}$ and 31 neonates on sildenafil, showed that the latter was more effective in the treatment of PPHN, with regard to time to adequate clinical response and duration of mechanical ventilation [21]. The present work identified both therapies as safe and effective lines of management in PPHN. Both groups showed significant improvement of their EPAP.

\section{Conclusions}

We concluded that both MgSO4 and sildenafil can be used as effective and safe in therapies in PPHN. Both therapies showed comparable outcomes as regards survival rates and side effects. However EPAP was significantly lower five days after therapy in neonates receiving sildenafil as compared to those receiving MgSO4. Sildenafil was associated with a significantly shorter duration of ventilation and interval to improvement of arterial blood gases.

\section{References}

1. Jones KL: Persistent pulmonary hypertension of the newborn: In :Kleigman R.M., Behrman R.E., Jenson H.B., Stantan B.E., eds. (2007): Nelson text book of pediatrics. 18th ed. Saunders: Philadelphia, PA. 
2. Finer NN, Barrington KJ. Nitric oxide for respiratory failure in infants born at or near term. Cochrane Database Syst Rev. 2001(2):CD000399.

3. Konduri GG, Kim UO. Advances in the diagnosis and management of persistent pulmonary hypertension of the newborn. Pediatr Clin North Am. 2009;56(3):579600 , Table of Contents.

4. Kinsella JP, Abman SH. Inhaled nitric oxide therapy in children. Paediatr Respir Rev. 2005;6(3):190-198.

5. Chambers CD, Hernandez-Diaz S, Van Marter LJ, Werler MM, Louik C, Jones KL, Mitchell AA. Selective serotonin-reuptake inhibitors and risk of persistent pulmonary hypertension of the newborn. N Engl J Med. 2006;354(6):579-587.

6. Chandran S, Haqueb ME, Wickramasinghe HT, Wint $Z$. Use of magnesium sulphate in severe persistent pulmonary hypertension of the newborn. J Trop Pediatr. 2004;50(4):219-223.

7. Reffelmann T, Kloner RA. Therapeutic potential of phosphodiesterase 5 inhibition for cardiovascular disease. Circulation. 2003;108(2):239-244.

8. Humbert M, Sitbon O, Simonneau G. Treatment of pulmonary arterial hypertension. $\mathrm{N}$ Engl J Med. 2004;351(14):1425-1436.

9. Abu-Osba YK. Treatment of persistent pulmonary hypertension of the newborn: update. Arch Dis Child. 1991;66(1 Spec No):74-77.

10. Tolsa JF, Cotting J, Sekarski N, Payot M, Micheli JL, Calame A. Magnesium sulphate as an alternative and safe treatment for severe persistent pulmonary hypertension of the newborn. Arch Dis Child Fetal Neonatal Ed. 1995;72(3):F184-187.

11. Daffa SH, Milaat WA. Role of magnesium sulphate in treatment of severe persistent pulmonary hypertension of the neoborn. Saudi Med J. 2002;23(10):1266-1269.

12. Wu TJ, Teng RJ, Tsou KI. Persistent pulmonary hypertension of the newborn treated with magnesium sulfate in premature neonates. Pediatrics. 1995;96(3 Pt 1):472-474.

13. Carroll WD, Dhillon R. Sildenafil as a treatment for pulmonary hypertension. Arch Dis Child. 2003;88(9):827828.

14. Abrams D, Schulze-Neick I, Magee AG. Sildenafil as a selective pulmonary vasodilator in childhood primary pulmonary hypertension. Heart. 2000;84(2):E4.

15. Keller RL, Hamrick SE, Kitterman JA, Fineman JR, Hawgood S. Treatment of rebound and chronic pulmonary hypertension with oral sildenafil in an infant with congenital diaphragmatic hernia. Pediatr Crit Care Med. 2004;5(2):184-187.

16. Baquero H, Soliz A, Neira F, Venegas ME, Sola A. Oral sildenafil in infants with persistent pulmonary hypertension of the newborn: a pilot randomized blinded study. Pediatrics. 2006;117(4):1077-1083.

17. Oliver J, Webb DJ. Sildenafil for "blue babies". Such unlicensed drug use might be justified as last resort. BMJ. 2002;325(7373):1174.

18. Castillo, J; Herrera, R; Concha E; Valencia, P; Torbati, D; Soliz, A (2005): Oral Sildenafil treatment as an alternative to inhaled NO therapy for persistent pulmonary hypertension of the newborn. Pediatric Research; 58:420-6.

19. Shah PS, Ohlsson A. Sildenafil for pulmonary hypertension in neonates. Cochrane Database Syst Rev. 2011(8):CD005494.

20. Khorana M, Yookaseam T, Layangool T, Kanjanapattanakul W, Paradeevisut H. Outcome of oral sildenafil therapy on persistent pulmonary hypertension of the newborn at Queen Sirikit National Institute of Child Health. J Med Assoc Thai. 2011;94 Suppl 3:S64-73.

21. Uslu S, Kumtepe S, Bulbul A, Comert S, Bolat F, Nuhoglu A. A comparison of magnesium sulphate and sildenafil in the treatment of the newborns with persistent pulmonary hypertension: a randomized controlled trial. J Trop Pediatr. 2011;57(4):245-250. 